\title{
Pragmatic Functions of Presupposition in Advertising English
}

\author{
Liping Ge \\ Foreign Language College, Henan University of Technology \\ Zhengzhou 450001, Henan, China \\ E-mail: gewangliping@163.com
}

This article is financed by the Humanities and social science project of Henan Provincial Education Department, whose name is "the analysis of presupposition in advertising English" with the project number 2010-CH-044.

\begin{abstract}
The functions of advertisement always give rise to the fact that trust and co-operation between the interlocutors are limited or lacking. Presupposition is frequently employed in order to enhance function of advertising language implicitly because of its own special properties and characteristics. This article refers to the historical and theoretical background of the study of presupposition and indicates pragmatic functions of presupposition in advertising English.
\end{abstract}

Keywords: Presupposition, Advertising English, Pragmatic functions

The functions of advertisement, informing and persuading, always give rise to the fact that trust and co-operation between the interlocutors are limited or lacking. Advertisers are concerned about the way in which advertising language serves the function of advertisement effectively without causing the recipients' repulsion and resistance. Therefore presupposition is frequently employed in order to enhance the informative and persuasive function of advertising language implicitly because pragmatic functions of presupposition in advertising English will contribute a lot to such a dilemma.

\section{Introduction to Presupposition}

Originally presupposition is predominantly treated as an issue of the philosophy of logic or truth-based logic semantics, which means a proposition whose truth is taken for granted. In the early 1970s, the pragmatic study of presupposition emerged and have been urged. Many studies are made, which lead to varieties of definitions on pragmatic presupposition. They are treated as "the set of conditions that have to be satisfied in order for the intended speech act to be appropriate in the circumstance, or to be felicitous", "the speakers' shared background information", and "inferences about what is assumed to be true in the utterance rather than directly asserted to be true" (Peccei: 2000-19)

\section{Pragmatic Functions of Presupposition in Advertising English}

\subsection{Conciseness Function}

From advertisers' aspect, concise language means economy of cost; from readers' aspect, concise language is more interesting, more effective and more persuasive.

In Peccei's view, presupposition is inferences about what is assumed to be true". (Pecci, 2000) The fact that presupposition is a kind of inference contributed to the conciseness of advertising language because it needn't to be said on purpose and even can omit corresponding expression of such information accordingly.

Many advertisements contain pragmatic presuppositions that are not stated out. Take one of the most often-used syntactical structures in advertising language - imperative sentence for instance. The structure, like "Buy x" or "Do x", and "you will..." in advertisements means something more like the structures "You need X", "X will bring you..." or "You'll find comfort and relief with X". These presuppositions, unnecessary to be spoken out, make advertising language directly concise. And they bring immediate effectiveness to advertisers.

Presupposition-triggers also have the ability to make the advertising language concise. Each of the presupposition-triggers has a form of simple word(s), phrase(s) or grammatical construction(s), but each of them is heavy-loaded in meaning. And the presupposition triggered by it is quite often one (sometimes more than one) complete sentence(s). Peccei (2000)gives us an example in her pragmatics: 


\subsection{Interestingness Function}

Lively, vivid and aesthetic advertising language constituents are a main factor for arousing reader's interest. Presuppositions triggered by presupposition-triggers make the same assertion emerge in various forms. For example, the assertion like "kodak is Olympic color" can be realized in the following forms.

(2) Kodak is Olympic color.

(2a) People know Kodak is Olympic color.

(2b) How do you know kodak is Olympic color?

(2c) It is kodak that is Olympoc color.

(2d) We feel happy/pleased/surprised that kodak is Olympic color.

(2e) Why is kodak Olympic color?

Presupposed information combines with asserted information, which creates readers' involvement and humor in advertising language. For example,

(3) At sixty miles an hour the loudest noise in the new Rolls Royce come from the electric clock.

$>>$ There is a noise from the electric clock when Rolls Royce travels at sixty miles an hour.

This presupposition explodes the shortcoming of product, therefore, the advertisement much more easily attracts consumers' attention. Consumers will quickly find that the existence of the noise in the presupposition is reasonable, which doesn't influence the function of the car at all, on the contrary, reflects the high-quality of it. Thus reader's involvement and humor are produced in the process from consumers' not understanding to understanding.

\subsection{Enlargement Function}

Presupposition can enlarge the amount of advertising information because presupposition information hardly appears solely.

(4) Why suffer another summer? (Air conditioner)

(5) This year, I'll stop asking “Do I look fat?”(Slimming food)

The main information of (4) is the question itself, but the presupposition information is "(You) suffer another summer" and "(You) have suffered in the past summers. The assertion information in (5) is "this year I'll stop ask..." and the presupposition information is "I have asked before" and "I look fat". Each of these two examples has both assertion information and presupposition information. Therefore, presuppositions can enlarge the amount of advertisement information by increasing the advertising information density.

\subsection{Emphasis Function}

In communication, no matter in oral form or in written form, people convey certain information. The information can be classified into two kinds: given information and new information. As Halliday suggests (Halliday, 2001:116, 325-326), the speaker will order given information before new information. The "unmarked" sequencing of information structure is taken to be "given-new", which means the arrangement of information is in a sequence that is from given information to new information. The information focus is often arranged at the last lexical item of the new information that is put at the end of an utterance. Since this order is the most common way in sequencing information units and the most common way in marking the information focus, it is called "normal focus" or "unmarked focus."

However, advertisers often adjust the position of information focus in order to highlight or emphasize certain information. They may make the information focus falls on the other lexical items rather than the last one in the information units. Presupposition keeps a close relationship with information focus. The change of presupposition information determines the change of information focus. Therefore, one common method employed to mark information focus is to alter the position of presupposition information with the help of certain means, which include phonetic means, cleft sentence, implicit cleft, and some words like only or even. Therefore, the advertisement writers must know that the focus of the information is closely connected with the presuppositions in the advertisements: the change of presupposition determines the position of the focus of the information; conversely, the focus of the information changes with the change of presupposition.

According to relevance theory, the placement of information in the advertisement should create some contextual effects in the hearer and minimize the processing efforts it involves. That is to say, successful advertisement should try to produce the largest contextual effects on the consumers and at the same time, the consumer's 
processing efforts involved in decoding the information and inferring the additional meanings should be maintained at the minimal level. Practically speaking, presupposed information and asserted information should be used properly in order to achieve maximal advertising effects.

In a word, presupposition determines the content and position of information focus of an advertisement. The change in presupposition means the corresponding change in the information focus. With different information focuses, an advertisement emphasizes particular part of its information to meet different needs of customers. The change in presupposition can be brought about by some linguistic means.

\subsection{Euphemism Function}

In order to push the advertised products, sometimes the advertisement writers have to point out the undesired states in which the consumers are. Without doubt, doing so will threaten the face of the consumers, engendering the antipathy of them.

According to Brown and Levinson (1987), politeness is very important for the success of the communication and politeness involves us showing an awareness of other people's face wants. Here face refers to our public self image, including positive face and negative face. By positive face, it means that we have the need to be accepted and liked by others, and to feel that our social groups share common goals while negative face refers to our right to independence of action and our need not be imposed by others. In a nutshell, in order to make communication more successful, mitigating devices and face-saving acts are indispensable.

This is to say, in the process of writing the advertisement, the advertisement writers must take the consumers' face wants into consideration by employing mitigating devices and face-saving acts such as circumlocution. However, for the advertisement writers, presupposition is a very effective means of serving this kind of purpose in that it can mitigate the tones of the claims, thus making the language of advertising indirect and roundabout. For example:

(60) The fast, gentle, long-lasting way to eliminate your unsightly hair and keep your skin looking smooth, silky and sensual. Hair off, by Larry Mathews."

This advertisement presupposes that you have unsightly hair. This kind of presupposed information will of cause occasion people's antipathy if they are told so directly because this will endanger their faces and embarrass them greatly. However, this kind of antipathy will be diminished or diverted because it is only presupposed and not asserted by the speaker or writer and the focus of information in the advertisement is on the asserted information that using Hair off, by Larry Matthews can keep your skin looking smooth, silky and sensual. Thus, the purposes of advertising have been achieved successfully without endangering the faces of consumers.

\subsection{Concealment Function}

Sometimes advertisers conceal specific advertising information deliberately to achieve certain effect and presupposition hence is employed. Why presupposition serves the purpose of concealment is that presupposition is subjective in essence. Presupposition closely connects with the speaker's belief, attitude and intention. In addition, it comes from people's knowledge about the way language users conventionally interpret the words and structures that trigger it, so presupposition can be quite "sneaky". It has the features of concealment and so it is employed to cover some facts in advertisement.

(61) A: What make this World Business Class so special?

\section{B: You own experience. (Dutch Royal Airlines)}

(61') B' This World Business Class is not special.

When the first speaker raises the question, he takes that "something makes this World Business Class so special" and "this World Business Class is so special" for its presupposition information. Since the presupposition is the assumption made by the speaker, it has several possibilities in authenticity and reliability. First, the presupposition information can be an actually existing fact. Secondly, it can be considered as a truth in case that the speaker really does not know what the real situation is. Thirdly, it can be that the speaker realizes it is not know what the real situation is. Anyway, the speaker takes it as a fact when he uses this presupposition in his advertisement. Then the "truth" with several possibilities in its authenticity possesses concealment to its potential readers or its listeners to certain extent.

Once they accept the advertisers' utterance, the recipients accept the presupposition in it because these potential presuppositions are automatically assigned to the utterance. In order to make sure a potential presupposition to become an actual proportion, people have to test it against the information in real context. Unless they get enough background information on the authenticity of presupposition and offer some assertion contradict to the 
presupposition, like the answer offered by B' in example (61'), the presupposition remains truth. Mey. J points out generally speaking, people never think much about what is presupposed. People do not have to go "presupposition-hunting" in order to understand an utterance. This happens only when people get stuck and perhaps have to invoke a metapragmatic constraint. However, metapragmatically questioning an interlocutor's presuppositions is a dangerous sport, inasmuch it may threaten the "face" of the conversational partner. (Mey, 993:188) Moreover, in daily life, consumers would not have the intention to investigate into all the presuppositions in an advertisement before they actually buy the advertised goods because the investigation will be time and effort taking. Therefore, advertisers make good use of the customers' psychology of unwilling to take too much trouble, and conceal some specific information in the form of presupposition that they believe their customers would take for granted most of the time.

\subsection{Persuasion Function}

Presupposition information contained in an utterance has the function of persuasion in an easy and a concealable way. All questions have inner presuppositions, and they are persuasive. Frequently they are regarded as "very useful for interrogators or trial lawyers (Yule, 2000, 8:132). It is the same in advertisements. Loftus once made an experiment to explain the inducibility of presupposition. (Loftus, 1975:560-572).

The tested objects were divided into two groups after they finished seeing a short film about traffic accident: the questions for the first group are

(62) a. How fast was the car going when it turned right?

b. Did you see a stop sign?

The questions for the second group are:

(63) a. How fast was the car going when it ran the stop sign?

b. Did you see the stop sign?

Although the second question for each group is the same. Only 35\% of the subjects in first group answer yes; while 53\% of the second group answer yes. The reason for this is that "stop sign" in the second question of (63) is one of the speaker's presuppositions in its first question. The ratio from the experiment shows that presupposition has a strong leading and persuasive function. Advertisers make use of this feature, and they employ presuppositions in their advertisements to show their point of views that can force the advertisement recipients into the designed mode of thinking, and that can influence their judgment. The presupposition in the following example serves such a function.

(64) Why Sony, when they could have any TV in the world? (Sony TV set)

In asking this question, the advertisers have presumed that people would like to use Sony TV Set even though they could have any other TV Set in the world as a fact. Therefore, this fact is roundabout way in eulogizing the subscribed TV. According to the result of Loftus' experiments, people will have a greater tendency in accepting the information that is put in the form of presupposition.

According to stylistic analyses, one feature of advertising language is the high frequency in the use of questions. One explanation to this phenomenon is that all questions imply presuppositions, in which the advertisers often skillfully advertise their products. Notice such kind of advertisements with presupposition triggers by questions like "Doesn't your wife recall the KISS you gave to her" and "Do you regret that you have a easier life with XX" which position the readers to admit to the presupposed act whether answer "yes" or "no" to these questions and notice the advertisement with a question like "How do you keep yourself so young and beautiful", which presupposes that the person who will answer the question looks young and beautiful and she has done something to keep herself young and beautiful. When the advertisement recipients answer the questions (only answer the questions as they required) of the advertisements, they confirm to the advertiser's presupposition.

Because presuppositions have the ability to survive under negation or question, it takes a lot of work to deny every presupposition in questions and many presuppositions go unchallenged. Therefore, presupposition is a powerful tool in persuading people for an advertisement.

\subsection{Self-protection Function}

In order to distinguish their own advertisements and get attention from customers in a fierce competition in advertising field, advertisers spare no efforts in publicizing the merit of their products. This leads to the employment of some advertising measures like hyperbole and comparison. Hyperbole is a kind of rhetorical device often used in advertisements. It is the deliberate use of overstatement or exaggeration to achieve the goal 
of information emphasis. By so doing, the advertisement will leave a very deep impression on the minds of the consumers; however, it may also be very repulsive to the consumers. Therefore, here presupposition can play its role again because it can downgrade the degree of the laudatory words, phrases and expressions and make the advertisement at least appear to be more objective. For example,

(65) And it's the reason why millions of Americans are falling in love with the first really new bed in 75 years: our high-tech weightless sleep system.

In the above excerpt from an advertisement for Tempur-Pedic bed, it is obvious that certain seemingly exaggerated information is conveyed by factive presupposition and existential presupposition. Needless to say, such expressions as "millions" of and "the first really new" etc. will undoubtedly give the consumers an impression that the advertised product is perhaps exaggerated and doubts will be thrown on the creditability of the advertisement. However, if such information is transmitted through presupposition, the exaggeration or praise of the properties of the product will be somehow downgrade because these pieces of information are not directly asserted. In other words, factive presupposition in this advertisement is manipulated properly to achieve maximal advertising effects.

It is clear from the discussion and the examples given the presupposition is a linguistic device that can be used to imply that certain conditions exist or that certain things have happened or have not happened. It is therefore a useful way of creating the largest contextual effect in recipients with minimum processing effort to achieve the maximum function of advertisement.

\section{References}

Brown, P. \& S. Levinson. (1987). Politeness: some universals in Language Usage. Cambridge: Cup.

Givon, T. (1984). The pragmatics of Referentiality. In Schffrin, D. (ed.).

Goddard, A. (1998). The language of Advertising. London and New York: Routledge.

Grice, P. (1989). Studies in the Way of Words. Cambridge: Harvard University Press.

Leech, G.N. (1983). Principles of Pragmatics. London: Longman.

Peccei, J.S. (2000). Pragmatics. London and New York: Routledge.

Stalnaker, R. (1973). Pragmatic Presuppositions. New York: New York University Press. 